\title{
TERAPIAS CELULARES PARA LIMITAR LA DEGENERACIÓN DE LOS FOTORRECEPTORES
}

\section{CELL-BASED THERAPIES TO LIMIT PHOTORECEPTOR DEGENERATION}

\author{
LUND R ${ }^{1}$
}

Las primeras investigaciones sobre trasplante subretiniano de células a ojos de mamíferos para el tratamiento de la degeneración retiniana datan de la década de 1980. En aquellos estudios se introducían células del epitelio pigmentario de la retina (EPR) en el espacio subretiniano de ratas Royal College of Surgeons (RCS), un modelo animal de degeneración de fotorreceptores debida a disfunción del EPR. Fue interesante observar que las células del EPR trasplantadas ralentizaron la pérdida de fotorreceptores, presumiblemente porque funcionaban como sustitutas del EPR disfuncional (1). La rata RCS sirve ahora como modelo genérico de degeneración de los fotorreceptores, pero resulta especialmente interesante para el estudio de la degeneración macular asociada a la edad (DMAE), en la que se piensa que la pérdida de visión es consecuencia de una alteración del funcionamiento de las células del EPR. Dada la eficacia con la que las células del EPR ralentizaban la degeneración en ratas RCS, se aplicó el método a pacientes con DMAE avanzada, aunque con pocos indicios de éxito.

Los resultados de los estudios en seres humanos ponen de relieve varios problemas importantes a los que debe prestarse especial atención antes de poder prever nuevos avances. En primer lugar, hay que evaluar detenidamente el uso de modelos animales adecuados para la investigación inicial de la eficacia de las terapias celulares. Asimismo, debe tenerse en cuenta la procedencia de las células que se utilizarán en las investigaciones. Es preciso hacer especial hincapié en las determinaciones funcionales de la eficacia y la seguridad. Por último, debe estudiarse detenidamente la forma de trasladar el tratamiento de modelos de roedores en el laboratorio a pacientes en un entorno clínico. Ello incluye definir el grupo concreto de pacientes que más se beneficiarían de aquél.

\section{DETERMINACIONES FUNCIONALES}

En los primeros estudios con ratas RCS, la eficacia del trasplante de células se evaluó únicamente midiendo el espesor de la capa nuclear externa, que en los roedores comprende más de un $95 \%$ de bastones. Estudios recientes hacen ahora más hincapié en medir la función visual en estos animales, particularmente la relacionada con los conos. En la evaluación de dicha función se emplean tres medidas de interés clínico: la agudeza visual, los umbrales de luminancia en el campo visual y el electrorretinograma (ERG).

La agudeza visual se determina mediante una prueba de optomotricidad, exploración comportamental que mide la respuesta optomotora del animal a una rejilla sinusoidal rotatoria. La prueba ofrece un medio no invasivo de determinar la agudeza visual durante un periodo de tiempo en un gran número de animales. Los registros del umbral de luminancia determinan la sensibilidad relativa de la retina en el campo visual. En este caso, las respuestas se registran mediante electrodos colocados en la zona del colículo superior, región cerebral con un mapa bien definido del campo visual. Esta prueba puede utilizarse para determinar la eficacia local de la terapia celular en el mantenimiento de la fun-

\footnotetext{
${ }^{1}$ Departamento de Oftalmología. Casey Eye Institute. Oregon Health \& Science University. Portland, OR 97239. Estados Unidos. E-mail: lundr@ohsu.edu
} 
ción retiniana. Por último, se mide la función visual a nivel celular utilizando registros electrorretinográficos (ERG) de campo completo. Los ERG permiten evaluar la actividad eléctrica, fundamentalmente la de los fotorreceptores, las células bipolares y las células amacrinas.

\section{PROCEDENCIA DE LAS CÉLULAS}

Los trabajos iniciales con células del RPE recién recolectadas mostraron que era preciso obtener células de ojos fetales. Sin embargo, el uso de tejido fetal no sólo suscita problemas logísticos y éticos, sino que entraña el riesgo de transmitir agentes infecciosos que no puedan ser detectados adecuadamente en el plazo que permite la técnica. Estos escollos impulsaron la exploración de diversas fuentes renovables de células que pueden producirse a escala comercial y ser sometidas a un riguroso examen antes de su implantación.

Se han estudiado varios de estos tipos celulares para determinar su eficacia en terapias celulares para las degeneraciones retinianas (2). Pensando en los grupos de pacientes aquejados de degeneración macular, una primera estrategia consistió en reemplazar las células del EPR con líneas celulares del EPR. Posteriormente se estudiaron otros tipos de células, algunos de los cuales no hay duda de que funcionan o pueden modificarse para que funcionen como células productoras de diversos factores de crecimiento. Dadas las abundantes pruebas de que la inyección de factores de crecimiento desempeña un papel importante en la ralentización de la degeneración en modelos animales de retinosis pigmentaria, el uso de células que los sintetizan ofrece un sistema alternativo y continuo de liberación de dichos factores.

De entre las células con fenotipo RPE, las que logran preservar la agudeza visual, el umbral de luminancia y el ERG, y dar respuesta a los diversos problemas de seguridad, son un conjunto de líneas celulares derivadas de células madre embrionarias (3). Estas células cumplen los criterios de seguridad que se exponen a continuación y se muestran eficaces en modelos murinos de degeneración macular. Se están estudiando para su posible aplicación clínica.

Un segundo grupo de células, más diverso, funciona mediante la producción de factores de crecimiento. Las primeras que se investigaron fueron las células de Schwann (2), productoras de varios fac- tores que ayudan a la supervivencia de los fotorreceptores. Logran preservar la visión y ofrecen la posibilidad de ser implantadas como injerto autólogo, con lo que se reducen al mínimo los problemas de seguridad, entre ellos las reacciones inmunitarias; sin embargo, el proceso de preparación es más complejo y supone extirpar un nervio periférico, aislar las células y cultivarlas. Otras células que pueden funcionar de manera similar son las aisladas del estroma del cordón umbilical, que son eficaces, fácilmente renovables y estables (4). Las derivadas de tejido prosencefálico fetal (5) pueden funcionar por sí mismas o ser transfectadas con el gen de factores como el factor neurotrófico derviado de la glía (GDNF) para aumentar su eficacia. Resulta interesante el hecho de que, una vez trasplantada, esta célula adopte algunas de las características de las células del RPE, lo que abre la posibilidad de que exprese dos funciones distintas.

Esta relación de tipos celulares dista mucho de ser exhaustiva: se están estudiando otros que pueden ser adecuados para inyectarlos en el espacio subretiniano, entre ellos los que se han utilizado en ensayos clínicos con otros tejidos. También es importante el hecho de que algunas células, como los fibroblastos y las células aisladas de la placenta, no tienen ningún efecto en la preservación de los fotorreceptores: hay comportamientos selectivos.

\section{CONSIDERACIONES SOBRE SEGURIDAD}

Con todos los tipos celulares es preciso tener en cuenta algunas cuestiones de seguridad. ¿Cuánto tiempo sobreviven las células de donante? ¿Muestran algún signo de crecimiento incontrolado a lo largo del tiempo, incluidas transformaciones tumorales? (En el caso de las células derivadas de células madre embrionarias, interesa saber si pueden formar teratomas.) ¿Se diseminan desde el lugar de inyección, tal vez invadiendo cavidades oculares o del resto del organismo en las que podrían causar efectos secundarios? Es preciso estudiar la línea celular para determinar si el fenotipo es estable o hay signos de alteraciones cromosómicas tras divisiones celulares progresivas, así como someterla a una detección lo más completa posible de agentes patógenos transmisibles. Por último, las células deben producirse según las normas establecidas de Buenas Prácticas de Fabricación (BPF). 


\section{ADAPTACIÓN DE TERAPIAS CELULARES UTILIZADAS EN ROEDORES AL SER HUMANO}

No es sencillo adaptar terapias utilizadas en modelos de roedores para su uso en el ámbito clínico, como quedó patente tras el fracaso de los mencionados ensayos clínicos en pacientes con DMAE. No cabe duda de que hay que resolver los problemas de seguridad a los que se ha aludido, así como la cuestión de la tolerancia inmunitaria. Por otra parte, el abordaje transescleral empleado para introducir las células en los ojos de roedores no resultaría adecuado en el ser humano. Lo ideal sería un abordaje transvítreo. Para resolver estos problemas es interesante plantearse estudios en primates no humanos, cuyos ojos tienen una estructura muy semejante a la del ojo humano, incluida la presencia de mácula. Por otra parte, la capacidad de las terapias celulares de liberar factores tróficos permite que las células puedan aplicarse a un grupo de pacientes más amplio, a diferencia de la terapia génica, que se limita a corregir un trastorno genético concreto. Como ocurre con toda extrapolación clínica, es preciso atenerse a ensayos clínicos correctamente diseñados y publicados, con criterios de evaluación objetivos y pertinentes. Dada la magnitud de la tarea, lo ideal es llevarla a cabo con socios comerciales.

En conjunto, este campo exhibe un gran dinamismo, orientado a generar tratamientos clínicos efica- ces. Se han identificado células útiles, se han resuelto en gran medida los problemas para trasladar la terapia del laboratorio a la clínica, y hay ensayos clínicos en marcha o previstos. Esta estrategia terapéutica ayudaría a estabilizar la situación ocular en pacientes con pérdida progresiva de fotorreceptores y allanaría el camino hacia un objetivo más complejo: la reposición de fotorreceptores una vez que han desaparecido.

\section{BIBLIOGRAFÍA}

1. Li LX, Turner JE. Inherited retinal dystrophy in the RCS rat: prevention of photoreceptor degeneration by pigment epithelial cell transplantation. Exp Eye Res 1988; 47: 911-917.

2. Lund RD, Wang S. Cell-based therapies to restrict to the progress of photoreceptor degeneration. In: TombranTink J, Barnstable CJ. Retinal degenerations: Biology, Diagnostics, and Therapeutics. Totowa, NJ, USA: Humana Press; 2007; 17: 319-344.

3. Lund RD, Wang S, Klimanskaya I, Holmes T, Ramos-Kelsey $R, L u B$, et al. Human embryonic stem cell-derived cells rescue visual function in dystrophic rats. Cloning Stem Cells 2006; 8: 189-199.

4. Lund RD, Wang S, Lu B, Girman S, Holmes T, Sauvé Y, et al. Cells isolated from umbilical cord tissue rescue photoreceptors and visual functions in a rodent model of retinal disease. Stem Cells 2007; 25: 602-611.

5. Gamm DM, Wang S, Lu B, Girman S, Holmes T, Bischoff $N$, et al. Protection of visual functions by human neural progenitors in a rat model of retinal disease. PLoS ONE 2007; 2: e338. 